\title{
Uso de produto à base de alho associado à poda no desempenho de videiras finas no oeste paranaense
}

\author{
Thomas Favaretto Bueno ${ }^{1}$, Fabíola Villa ${ }^{*}$, Danimar Dalla Rosa ${ }^{1}$, Diego Ricardo Stumm ${ }^{1}$
}

10.1590/0034-737X201764040012

\begin{abstract}
RESUMO
A vitivinicultura é uma atividade relevante, e de grande potencial, no oeste do Paraná, mas há carência de adequações do manejo cultural das videiras finas, nessa região. Diante do exposto, objetivou-se, com este trabalho, avaliar as intensidades e as épocas de poda, associadas ao uso de produtos para quebra de dormência, em videiras finas cvs. 'Cabernet Franc' e 'Cabernet Sauvignon'. Foram realizados dois experimentos, nos quais se utilizou o delineamento experimental em blocos casualizados: o primeiro em esquema fatorial 3 × 2 (três intensidades de poda, sendo poda curta, longa e mista $\mathrm{x}$ dois produtos comerciais para quebra de dormência $\left(\right.$ Dormex $^{\circledR} \mathrm{e}$ Natualho ${ }^{\circledR}$ ), contendo cinco blocos e uma planta por bloco, totalizando 30 plantas do cv. 'Cabernet Franc', enxertadas sobre o porta-enxerto 'RR 101-14'. A poda e a aplicação dos produtos, por pulverização, até completo molhamento dos sarmentos, foram realizadas em 17 de agosto de 2013. O segundo experimento constou de esquema fatorial $4 \times 2$ (quatro épocas de poda $\mathrm{x}$ dois produtos comerciais para quebra de dormência), contendo quatro blocos e uma planta por bloco, totalizando 32 plantas do cv. 'Cabernet Sauvignon', enxertadas sobre o porta-enxerto 'RR 101-14'. As plantas do segundo experimento foram submetidas apenas a poda curta. Após a poda, nos dois experimentos, avaliaram-se as características vegetativas, como número de gemas por planta, número de brotações por planta, estádio fenológico de "gema algodão", utilizado como padrão de brotação, percentagem de gemas brotadas e tempo transcorrido da poda até a estabilização da brotação (dias). O extrato de alho não apresentou eficiência na quebra de dormência das plantas. O cv. 'Cabernet Franc' apresentou melhor desenvolvimento vegetativo, quando submetido à poda curta. A última época de poda propiciou melhor desenvolvimento vegetativo do cv. 'Cabernet Sauvignon'.
\end{abstract}

Palavras-chave: brotações; extrato de alho; Vitis vinifera.

\section{ABSTRACT}

\section{Use of garlic-based product associated with pruning on the performance of fine grapevines}

The wine industry is a very important activity on the national scenery, having important role in diversification and incorporation of income for small farms. The aim of the present study was to evaluate intensities and pruning times associated with the use of products for bud breaking dormancy in Cabernet Franc and Cabernet Sauvignon grapevine varieties in Marechal Cândido Rondon, Paraná State, Brazil. Two experiments were carried out, in which the experimental design was a randomized block design. The first experiment was done in a $3 \times 2$ factorial scheme (three pruning intensities, (short, long, and mixed pruning) $\times$ two commercial products for bud breaking dormancy (Dormex ${ }^{\circledR}$ and Natualho ${ }^{\circledR}$ ), containing five blocks and one plant/block, totaling 30 plants of Cabernet Franc grapevine variety grafted onto 'RR 101-14' rootstocks. Pruning and application of the products through spraying until complete wetting of the plants were carried out on August 17, 2013. The second experiment consisted of a $4 \times 2$ factorial scheme (four pruning

Submetido em 12/06/2015 e aprovado em 23/06/2017

'Universidade Estadual do Oeste do Paraná, Centro de Ciências Agrárias, Marechal Cândido Rondon, Paraná, Brasil. thomas.bueno@hotmail.com; fvilla2003@hotmail.com; danimardr@hotmail.com; diegostumm@ hotmail.com

*Autora para correspondência: fvilla2003@hotmail.com 
times $\times$ two commercial products for bud breaking dormancy), containing four blocks and one plant/block, totaling 32 plants of Cabernet Sauvignon grapevine variety, grafted on the 'RR 101-14' rootstocks. After pruning in the two experiments, the following vegetative characteristics were evaluated: number of buds/plant; number of shoots/plant; phenological stage of "cotton bud", used as sprouting pattern; percentage of sprouted buds; and length of time from pruning to stabilization of sprouting. Garlic extract did not show efficiency in the plant bud breaking dormancy. Variety Cabernet Franc showed better results in vegetative parameters when subjected to heavy pruning. The last pruning time showed better results for the vegetative characteristics of variety Cabernet Sauvignon.

Key words: shoots; garlic extract; Vitis vinifera.

\section{INTRODUÇÃO}

O Estado do Paraná, na safra 2013, ocupou o quinto lugar nacional na produção de uva, representando $5 \%$ do total (IBGE, 2014). O polo de viticultura paranaense situase no norte do estado, onde predomina o cultivo de castas europeias de mesa, com destaque para o cv. 'Itália' (Protas \& Camargo, 2010). Na vinificação, o Paraná destaca-se no cultivo de castas americanas e híbridas, com resultados positivos na adaptação de cultivares finos para a elaboração de vinhos na região norte do estado, devido à possibilidade de se obter sucesso no cultivo desses cultivares nas regiões de clima subtropical (Werle et al., 2008).

Dentre os fatores que podem impedir o bom desempenho de um vinhedo, destaca-se a irregularidade da brotação, causada principalmente pela insuficiência do acúmulo de horas de frio para a superação da dormência (Botelho et al., 2002), de suma importância quando se trabalha com cultivares mais exigentes em frio, como os do grupo Cabernet, em regiões com invernos mais brandos, como é o caso do oeste paranaense. Atualmente, a cianamida hidrogenada é o produto mais utilizado para superação dessa dormência; entretanto, este composto é altamente tóxico ao homem e ao ambiente (Amberger, 2013; Botelho et al., 2002). No intuito de buscar substâncias alternativas, com menor impacto ambiental, o extrato de alho vem apresentando resultados promissores na quebra da dormência de fruteiras de clima temperado (Botelho \& Müller, 2007). Porém, esse produto precisa ser melhor avaliado em condições de campo.

Outro aspecto relevante do manejo para obtenção de resultados satisfatórios no cultivo de videiras é a execução da poda, pois, sem ela, a produtividade não é constante e os cachos são pequenos e de baixa qualidade (Euleuterio et al., 2010). Tendo em vista que cada cultivar adapta-se a um método específico de poda e que a escolha deste se dá, basicamente, em função do cultivar e das características de solo e clima do local de cultivo
(Euleuterio et al., 2010), são necessários estudos a respeito desse aspecto, especialmente quando se trabalha com cultivares que não são familiares em determinado local.

Diante do exposto, objetivou-se, com este trabalho, avaliar as intensidades e as épocas de poda, associadas ao uso de produtos para superação de dormência, em videiras finas cvs. 'Cabernet Franc' e 'Cabernet Sauvignon', no oeste paranaense.

\section{MATERIAL E MÉTODOS}

Foram realizados dois experimentos, em uma Fazenda Experimental localizada a $24^{\circ} 33^{\prime} 40^{\prime \prime} \mathrm{S}$, e 540.' $12^{\prime \prime} \mathrm{O}$, altitude de 420 metros; sendo o solo classificado como Latossolo Vermelho eutroférrico, pertencente ao grande grupo Latossolo (Embrapa, 2006). O município de Marechal Cândido Rondon, Paraná, apresenta clima subtropical úmido, $C f a$ segundo Köppen, as temperaturas mínimas médias variando entre 17 e $18^{\circ} \mathrm{C}$, e máximas médias entre 28 e $29^{\circ} \mathrm{C}$ (IAPAR, 2006). O pomar didático foi instalado em 2005, em sistema de condução em "Y", contendo quatro fios de arame, com espaçamento de $3 \times 1,2 \mathrm{~m}$.

Os tratos culturais foram realizados desde o início do ciclo produtivo e incluíram as práticas de controle de plantas daninhas, amarração de ramos, desnetamento e desponte de ramos, conforme recomendações de Leão (2010). O controle fitossanitário foi iniciado imediatamente após a poda, por amontoa e queima dos sarmentos retirados e, após o início das brotações, foram realizadas aplicações preventivas quinzenais de fungicida, de princípio ativo mancozebe (300 g 100 $\mathrm{L}^{-1}$ do produto comercial Mancozebe Sipcam $\left.^{\circledR}\right)$.

Foram realizados dois experimentos, nos quais se utilizou o delineamento experimental em blocos casualizados (DBC). O primeiro em esquema fatorial $3 \times 2$ (três intensidades de poda, sendo poda curta, longa e mista $\mathrm{x}$ dois produtos comerciais para quebra de dormência, sendo Dormex ${ }^{\circledR}$ na concentração de $30 \mathrm{mg} \mathrm{L}^{-1}$ e Natualho ${ }^{\circledR}$ (con- 
centração descrita na embalagem, contendo cinco blocos e uma planta por bloco, totalizando 30 plantas do cv. 'Cabernet Franc', enxertadas sobre o porta-enxerto 'RR 101-14'. A poda e a aplicação dos produtos, por pulverização até completo molhamento dos sarmentos, foram realizadas em 17 de agosto de 2013. O segundo experimento constou de esquema fatorial $4 \times 2$ (quatro épocas de poda, sendo estas nas datas 18/07/13, 01/08/13, 17/08/13 e 31/ 08/13 x dois produtos comerciais para quebra de dormência (Dormex ${ }^{\circledR}$ e Natualho ${ }^{\circledR}$ ), contendo quatro blocos e uma planta por bloco, totalizando 32 plantas do cv. 'Cabernet Sauvignon', enxertadas sobre o porta-enxerto 'RR 10114'. As plantas do segundo experimento foram submetidas apenas a poda curta.

Após a poda, nos dois experimentos, avaliaram-se as características vegetativas, como número de gemas por planta (contadas nos sarmentos podados), número de brotações por planta (contados semanalmente, desde a primeira brotação até a estabilização destas), estádio fenológico de "gema algodão" (proposto por Eichhorn \& Lorenz, 1984), utilizado como padrão de brotação, percentagem de gemas brotadas (relação entre número de brotações e total de gemas/planta) e tempo transcorrido da poda até a estabilização da brotação (dias) com o software Sisvar (Ferreira, 2011), sendo as comparações das médias realizadas pelo teste de Tukey, a $5 \%$ de probabilidade de erro.

\section{RESULTADOS E DISCUSSÃO}

\section{Experimento 1}

Na Figura 1, verifica-se, para o experimento com intensidades de poda x produtos para superação de dormência, nos tratamentos em que se aplicou o produto Dormex ${ }^{\circledR}$, uma estabilização mais rápida das brotações. Praticamente, onde se aplicou o produto, verificou-se a máxima percentagem de brotações aos 14 dias após a poda (DAP), enquanto que, nas plantas em que se aplicou o produto
Natualho ${ }^{\circledR}$, as brotações se estabilizaram somente aos 42 DAP.

Em estudos com produtos alternativos, Marini (2011) também verificou um atraso no início e na estabilização de brotações de videira fina cv. 'Cabernet Sauvignon' cultivada no Rio Grande do Sul e tratada com extrato de alho, em comparação com o observado com o uso do Dormex ${ }^{\circledR}$.

$\mathrm{O}$ atraso do início e da estabilização de brotações em videiras pode gerar ônus no momento da colheita dos cachos, por desuniformidade da maturação das uvas. Porém, em alguns casos, pode ser um fator positivo, proporcionando o escape de geadas tardias, que geralmente ocorrem no oeste paranaense, em função do maior tempo, até que todas as brotações se desenvolvam (Miele \& Mandelli, 2004).

$\mathrm{Na}$ Tabela 1, verifica-se maior percentagem de brotações das plantas às quais se aplicou o Dormex ${ }^{\circledR}$, bem como estabilização mais rápida das brotações, corroborando Marini (2011), que, ao trabalhar com superação de dormência de videira cv. Cabernet Sauvignon, verificou percentagem média de brotações de $76 \%$, para o extrato de alho, e de $77 \%$, para o Dormex ${ }^{\circledR}$, e tempo para estabilização das brotações de 39 dias.

A percentagem de brotação é a variável que dá indicativos de produtividade, logo posteriormente à poda, sendo que, nesta, pode-se dimensionar o número de gemas a serem deixadas, a fim de otimizar a produção, mantendo o equilíbrio entre qualidade e quantidade de frutos (Almanza-Merchán et al., 2010).

Além da utilização de produtos para superação de dormência de frutíferas temperadas, fatores ambientais também devem ser levados em consideração. Na Figura 2, observa-se o número de horas de frio acumuladas em Marechal Cândido Rondon, PR, em 2013, sendo 150 horas de frio até a aplicação dos tratamentos, e 170 no total.

Para a superação de dormência de videiras finas, são necessárias entre 336 e 504 horas de frio (Roberto et al.,

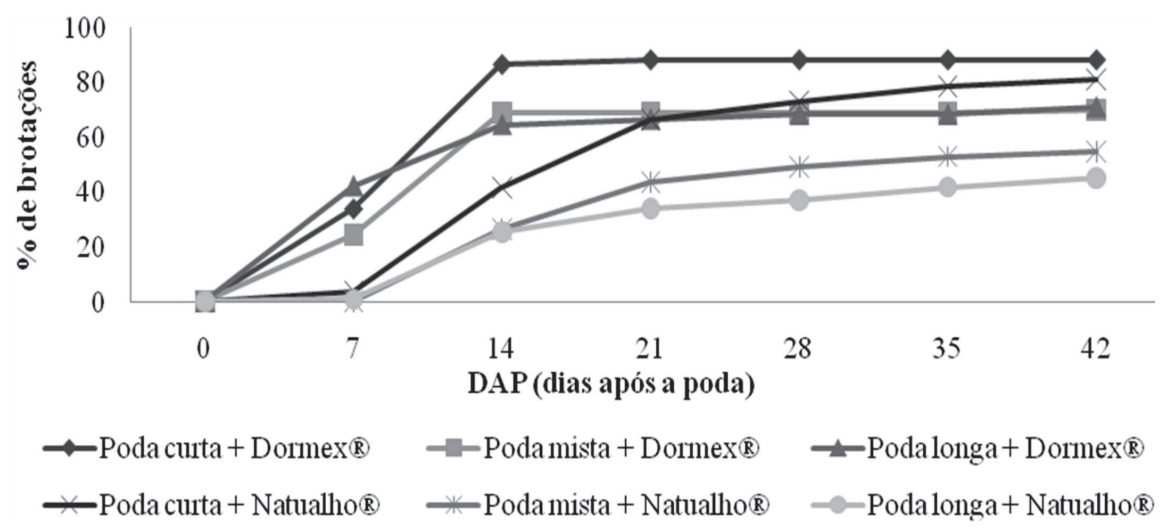

Figura 1: Percentagem média de brotações por planta de videira cv. 'Cabernet Franc', em função do tempo e em respostas a intensidades de poda e a produtos para superação de dormência. 
2002; Botelho et al., 2007), muito acima das 170 horas verificadas na Figura 2, associadas a produtos. Este fato pode explicar talvez porque o extrato de alho não proporcionou melhor eficiência nas brotações de videiras cv. Cabernet Franc. Botelho et al. (2007), ao estudarem a superação de dormência em estacas de videira cv. Cabernet Sauvignon, submetidas a horas de frio, confirmaram que a aplicação de extrato de alho apresentou eficiência nas brotações, alcançando $70 \%$ de gemas brotadas aos 35 DAP.

Na Figura 3, verifica-se diferença estatística da percentagem de brotações entre as intensidades de poda, sendo que a poda curta apresentou-se melhor que as demais. Isso confirma a recomendação de Sousa (1996), que indica o cordão esporonado, com duas gemas, como o melhor tipo de poda para o cv. 'Cabernet Franc'.

Videiras finas, submetidas à poda longa, emitem brotações primeiro nas gemas da extremidade, ocorrendo a inibição das gemas laterais, que podem brotar, mas com menor vigor e mais tardiamente (Miele \& Rizzon, 2013; Cañón et al., 2014).

Tonietto \& Czermainski (1993), ao testarem diferentes intensidades de poda para o cv. 'Cabernet Franc', em Bento Gonçalves, RS, verificaram que a percentagem de brotação decresceu à medida em que aumentou o número de gemas por vara, variando de $75 \%$, para a poda curta (cinco gemas), a 55\%, para a poda longa (15 gemas), corroborando resultados deste trabalho, em que os valores variaram de
$84,5 \%$ (poda curta) a 57,9\% (poda longa). A poda em videiras finas cv. Cabernet Sauvignon e Sauvignon Blanc apresentou melhores resultados no equilíbrio vegetativo/ produtivo, em estudos na Colômbia (Almanza-Merchán et al., 2014).

\section{Experimento 2}

Observam-se na Figura 4 os resultados para percentagem de brotações, referentes ao segundo experimento, em que se utilizaram épocas de poda versus produtos para superação de dormência. Pode-se verificar que as brotações levaram mais tempo para se estabilizarem, nas

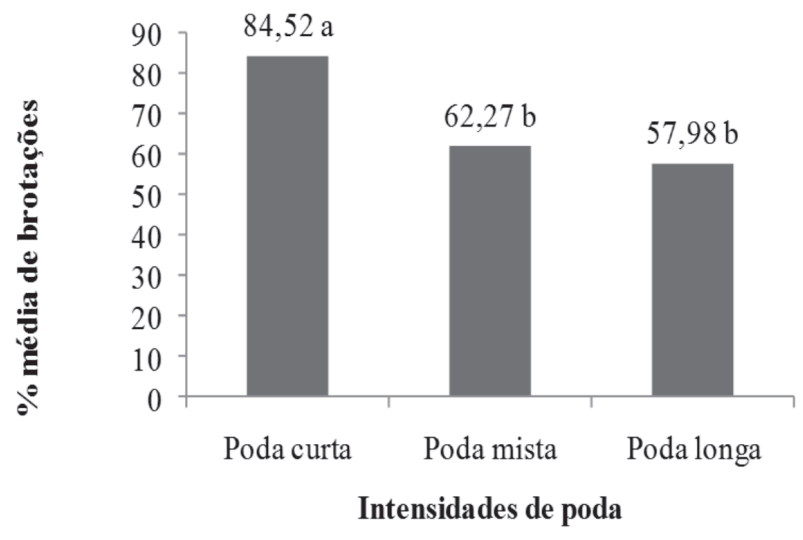

Figura 3: Percentagem média de brotações por planta de videira cv. 'Cabernet Franc', em resposta a intensidades de poda.

Tabela 1: Médias de percentagem de brotações e dias após a poda (DAP), para estabilizar o número de brotações de videira cv. Cabernet Franc

\begin{tabular}{lcc}
\hline Produtos & $\begin{array}{c}\text { Médias de percentagem } \\
\text { de brotações }\end{array}$ & $\begin{array}{c}\text { Médias de DAP para estabilizar } \\
\text { o número de brotações }\end{array}$ \\
\hline Dormex $^{\circledR}$ & $76,27 \mathrm{a}^{*}$ & $30,27 \mathrm{~b}$ \\
Natualho $^{\circledR}$ & $60,24 \mathrm{~b}$ & $47,47 \mathrm{a}$ \\
\hline Médias & 68,25 & 38,87 \\
\hline $\mathrm{CV}(\%)$ & 17,35 & 21,66 \\
\hline
\end{tabular}

*Médias seguidas de mesma letra minúscula na coluna não diferem entre si pelo Teste de Tukey, a 5\% de probabilidade de erro.

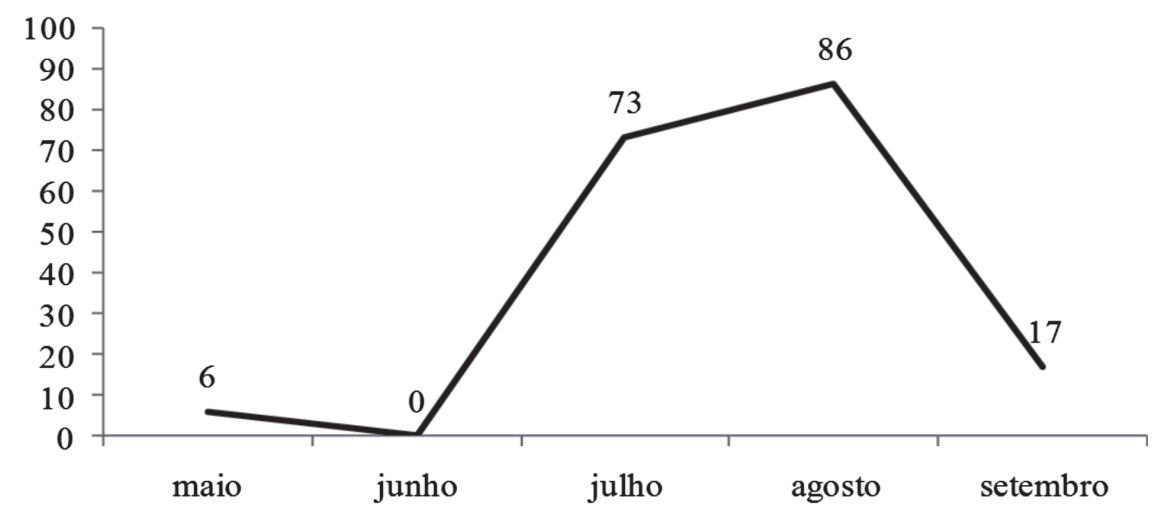

Figura 2: Número de horas com temperaturas mínimas abaixo de $7,2^{\circ} \mathrm{C}$, acumuladas no local dos experimentos em 2013. 
plantas às quais foi aplicado o Natualho ${ }^{\circledR}$, independentemente da época de poda.

$\mathrm{Na}$ Tabela 2, verifica-se percentagem de brotações para a $2^{\mathrm{a}}$ época de poda, maior que a da $3^{\mathrm{a}}$ época e, quanto ao tempo para estabilizar as brotações (DAP), observou-se que, na $4^{\mathrm{a}}$ época de poda foi superior à da $1^{\mathrm{a}}$ época. A menor percentagem de brotação verificada para a poda realizada mais cedo ( $1^{\text {a }}$ época), pode estar relacionada com o baixo nível de dormência das gemas e, consequentemente, ao amadurecimento inadequado dos ramos, por ocasião da quebra de dormência. A entrada em dormência, antes do reinício do ciclo vegetativo, parece necessária para uma adequada brotação das videiras, o que pode estar diretamente associado à mobilização de nutrientes das folhas senescentes para os órgãos de reservas, como raízes, troncos e ramos (Botelho et al., 2002).

A $4^{\mathrm{a}}$ época pode ser explicada como melhor na estabilização das brotações pelo fato de que ocorreram três geadas entre as datas de poda, que podem ser notadas pelas baixas médias de temperatura mínima de 10 e $11,4^{\circ} \mathrm{C}$, registradas nos meses de agosto e julho de 2013, respectivamente (Figura 5). Dessa forma, as videiras dos tratamentos que já haviam recebido a poda demoraram mais para brotar, pois a brotação é favorecida por temperaturas mais elevadas (Pedro Junior et al., 2014). Além disto, nesta época as plantas tiveram mais tempo para entrarem em um re-equilíbrio hormonal (Sozim et al., 2007) e, ainda, um número de horas de frio satisfeito.

Moura et al. (2011), obtiveram brotações mais rápidas para videiras finas de mesa cv. Juliana, em Jundiaí (SP), nos tratamentos que receberam a poda em agosto e setembro. Isso vem ao encontro dos aspectos positivos muitas vezes publicados em favor da poda tardia, como brotação mais uniforme, menor incidência de antracnose, menor probabilidade de danos por geadas, propiciando assim maior produtividade ao vinhedo.

Na Tabela 3, nota-se que, nas plantas às quais se aplicou o Natualho ${ }^{\circledR}$ para superação de dormência, as brotações demoraram mais até sua estabilização. Isso indica que este produto à base de alho não é tão eficiente, quanto a cianamida hidrogenada $\left(\right.$ Dormex $\left.^{\circledR}\right)$, para uniformizar as brotações de videiras finas, visto que, quanto maior a demora para seu estabelecimento, maior a sua desuniformidade. Como consequência deste fato, tem-se posteriormente um florescimento irregular, baixa frutificação e cachos de má qualidade.

Segundo Marodin et al. (2006), melhores resultados para brotações de gemas de vara foram verificados com

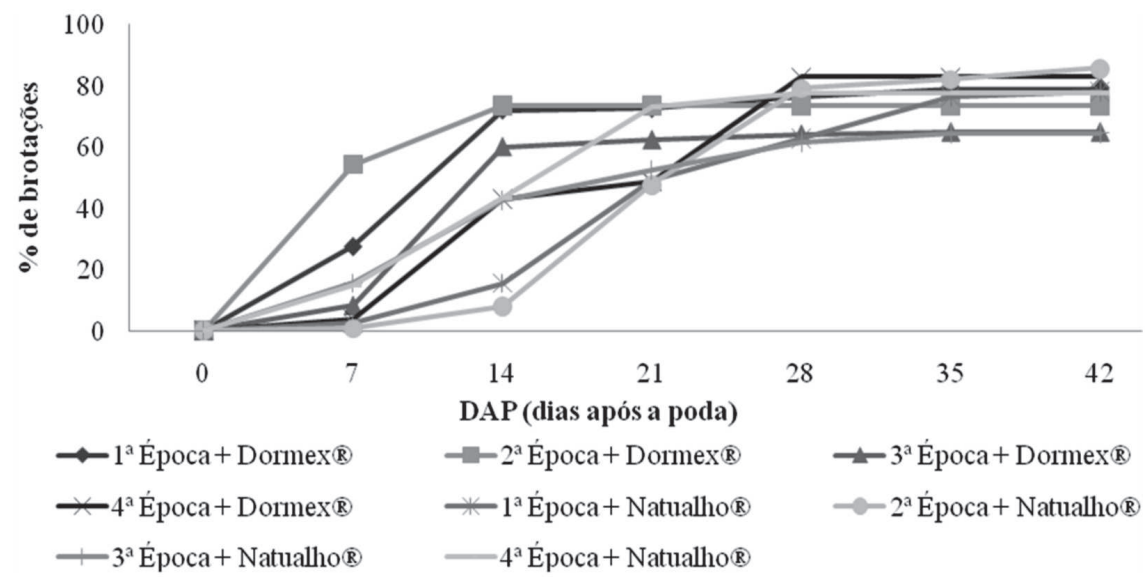

Figura 4: Percentagem média de brotações por planta de videira cv. 'Cabernet Sauvignon', em função do tempo e em respostas a épocas de poda e a produtos para superação de dormência.

Tabela 2: Médias de percentagem de brotações e de dias após a poda (DAP) para estabilizar número de brotações (dias) da videira cv. Cabernet Sauvignon

\begin{tabular}{lcc}
\hline Épocas de poda & $\begin{array}{c}\text { Médias de percentagem } \\
\text { de brotações }\end{array}$ & $\begin{array}{c}\text { Médias de DAP para estabilizar } \\
\text { as brotações }\end{array}$ \\
\hline $1^{\text {a Época }}$ & $78,49 \mathrm{ab}^{*}$ & $51,00 \mathrm{a}$ \\
$2^{\mathrm{a}}$ Época & $81,56 \mathrm{a}$ & $41,88 \mathrm{ab}$ \\
$3^{\mathrm{a}}$ Época & $64,75 \mathrm{~b}$ & $43,38 \mathrm{ab}$ \\
$4^{\mathrm{a}}$ Época & $80,21 \mathrm{ab}$ & $34,63 \mathrm{~b}$ \\
\hline Médias & 77,38 & 42,72 \\
\hline $\mathrm{CV}(\%)$ & 15,01 & 17,48 \\
\hline
\end{tabular}

*Médias seguidas de mesma letra minúscula na coluna não diferem entre si pelo Teste de Tukey, a 5\% de probabilidade de erro. 
1,75 e 2,0\% do produto Dormex ${ }^{\circledR}$, em 'Cabernet Sauvignon' e 'Pinot Noir', respectivamente, cultivadas em Garibaldi, RS. As concentrações de cianamida hidrogenada superiores a $1,5 \%$ ocasionaram uniformidade de brotação, independentemente do ano estudado. Resultados apresentados também por Mohamed et al. (2010), em regiões subtropicais, mostram a eficiência da utilização de $2 \%$ de cianamida na superação de dormência em videiras de mesa Superior Seedless.

Apesar de o extrato de alho apresentar resultados positivos na superação de dormência em videiras finas para mesa e processamento, torna-se ainda necessária a realização de trabalhos futuros, para definição de concentrações adequadas do produto comercial para cada região de cultivo, associação deste com manejo cultural, como épocas de poda, e buscas futuras de outras substâncias alternativas, com baixo impacto ambiental, podendo apresentar assim resultados promissores para este cultivo.

Tabela 3: Médias de dias após a poda (DAP) para estabilizar o número de brotações de videira cv. Cabernet Sauvignon', com o uso de produtos para superação de dormência

\begin{tabular}{lc}
\hline Produtos & DAP para estabilizar as brotações \\
\hline Dormex $^{\circledR}$ & $35,50 \mathrm{~b}$ \\
Natualho $^{\circledR}$ & $49,94 \mathrm{a}$ \\
\hline Média & 42,72 \\
\hline CV $(\%)$ & 17,48 \\
\hline
\end{tabular}

*Médias seguidas de mesma letra minúscula na coluna não diferem entre si pelo Teste de Tukey à $5 \%$ de probabilidade de erro.

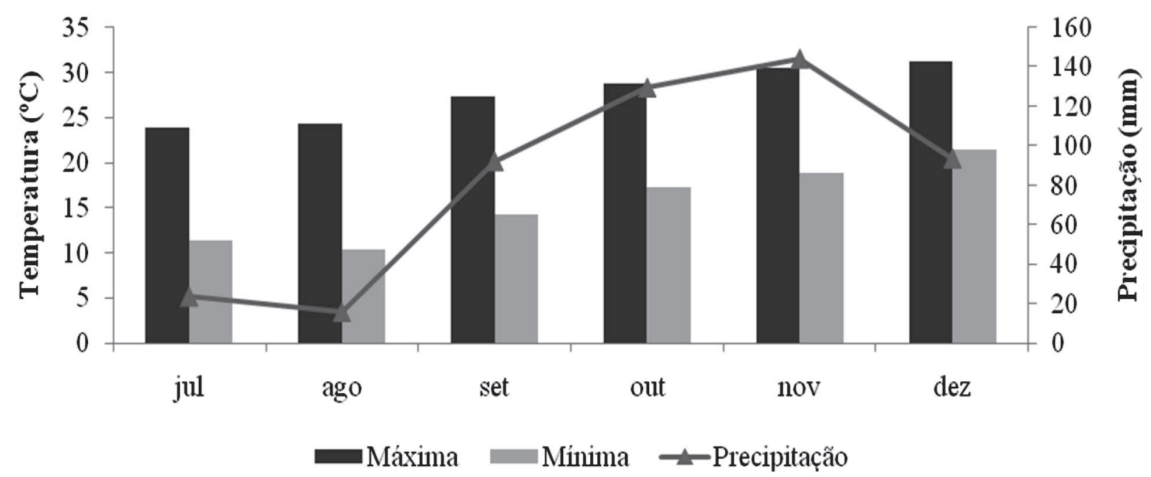

Figura 5: Temperaturas e precipitações mínimas e máximas referentes ao $2^{\circ}$ semestre de 2013.

\section{CONCLUSÕES}

O extrato de alho não apresentou eficiência na quebra de dormência das videiras finas, no oeste paranaense.

$\mathrm{O}$ cv. 'Cabernet Franc' apresentou melhores resultados das características vegetativas, quando submetido à poda curta.

A última época de poda (31/08/2013) apresentou melhores resultados para as características vegetativas do cv. 'Cabernet Sauvignon' na região oeste do estado do Paraná.

\section{REFERÊNCIAS}

Almanza-Merchán PJ, Serrano-Cely PA, Forero-Ulloa FE, Arango J \& Puerto ÁM (2014) Pruning affects the vegetative balance of the wine grape (Vitis vinifera L.). Agronomía Colombiana, 32:180-187.

Almanza-Merchán PJ, Serrano-Cely PA, Fischer G \& BalagueraLópez HE (2010) Rompimiento de la dormancia de yemas de vid (Vitis vinifera L.)mediante aplicaciones de extracto de ajo (Allium sativum L.) bajo condiciones del trópico alto. Revista Colombiana de Ciencias Hortícolas, 4:143-152.

Amberger A (2013) Cyanamide in plant metabolism. International Journal of Plant Physiology and Biochemistry, 5:01-10.
Botelho RV, Pires EJP \& Terra MM (2002) Brotação e produtividade de videiras da cultivar Centennial Seedless (Vitis vinifera L.) tratadas com cianamida hidrogenada na região noroeste do estado de São Paulo. Revista Brasileira de Fruticultura, 24:611-614.

Botelho RV \& Müller MML (2007) Extrato de alho como alternativa na quebra de dormência de gemas em macieiras cv. 'Fuji Kiku'. Revista Brasileira de Fruticultura, 29:37-41.

Botelho RV, Pavanello AP, Pires EJP, Terra MM \& Müller MML (2007) Effects of chilling and garlic extract on bud dormancy release in Cabernet Sauvignon grapevine cuttings. American Journal of Enology and Viticulture, 58:402-404.

Cañón PM, González ÁS, Alcalde JÁ \& Bordeu E (2014) Red wine phenolic composition: the effects of summer pruning and cluster thinning. Ciência y Investigación Agraria, 41:235-248.

Eichhorn KW \& Lorenz DH (1984) Phaenologische entwicklungsstadien der rebe. European and Mediterranean Plant Protection Organization, 14:295-298.

Embrapa - Empresa Brasileira de Pesquisa Agropecuária (2006) Centro Nacional de Pesquisa de Solos. Sistema Brasileiro de Classificação de Solos $2^{\mathrm{a}}$ ed. Rio de Janeiro, Embrapa Solos. 306 p.

Euleuterio MD, Gioppo M, Sozim M \& Malgarim MB (2010) Épocas e sistemas de poda na produção da videira cv. Bordô (ives). Revista de Engenharia e Tecnologia, 2:55-59.

Ferreira DF (2011) Sisvar: A computer statistical analysis system. Ciência \& Agrotecnologia, 35:1039-1042. 
IAPAR - Instituto Agronômico do Paraná (2006) Cartas climáticas do Paraná. Disponível em: <http://www.iapar.br/modules/ conteudo/conteudo.php?conteudo $=677>$. Acessado em: $10 \mathrm{de}$ maio de 2015.

IBGE - Instituto Brasileiro de Geografia e Estatística (2014) Levantamento sistemático da produção agrícola: pesquisa mensal de previsão e acompanhamento das safras agrícolas no ano civil 2013. Rio de Janeiro, IBGE. 84p.

Leão PCS (2010) Cultivo da videira: manejo da parte aérea. Disponível em: <http://sistemasdeproducao.cnptia.embrapa.br/ FontesHTML/Uva/CultivodaVideira_2ed/manejo_parte_aerea.html>. Acessado em: 15 de maio de 2015.

Marini J (2011) Efeito de diferentes doses de extrato de alho (Allium sativum L.) na superação de dormência de Cabernet Sauvignon (Vitis vinifera L.). Trabalho de Conclusão de Curso de Graduação. Instituto Federal de Educação, Ciência e Tecnologia do Rio Grande do Sul, Bento Gonçalves. 32p.

Marodin GAB, Guerra DS, Zanini CLD, Argenta F \& Grasselli V (2006) Brotação e produção das videiras 'Cabernet Sauvignon' e 'Pinot Noir' submetidas a diferentes concentrações de cianamida hidrogenada. Revista Brasileira de Fruticultura, 28:406-409.

Miele A \& Mandelli F (2004) Poda seca da videira. Disponível em: <http:www.cnpuv.embrapa.br/serviços/viticultura/podaseca.html>. Acessado em: 20 de maio de 2015.

Miele A \& Rizzon LA (2013) Intensidades da poda seca e do desbaste de cacho na composição da uva Cabernet Sauvignon. Revista Brasileira de Fruticultura, 35:1081-1092.

Mohamed HB, Vadel AM \& Khemira H (2010) Estimation of chilling requirement and effect of hydrogen cyanamide on budbreak and fruit characteristics of 'Superior Seedless' table grape cultivated in a mild winter climate. Pakistan of Journal Botany, 42:1761-1770.
Moura MF, Tecchio MA, Hernandes JL, Moura NF \& Seleguini A (2011) Comportamento produtivo da videira, cultivar Juliana, sobre três porta-enxertos em diferentes épocas de poda. Revista Brasileira de Fruticultura, 33:625-631.

Pedro Junior MJ, Hernandes JL, Blain GC \& Camparotto LB (2014) Produtividade, fenologia e maturação da 'Cabernet Sauvignon' para diferentes épocas de poda. Ciência e Técnica Vitivinicola, 29:09-15.

Protas JFS \& Camargo UA (2010) Panorama setorial 2010. Vitivinicultura Brasileira. Disponível em: <http:// www.ibravin.org.br/public/upload/downloads/1384347732.pdf>. Acessado em: 11 de junho de 2015.

Roberto SR, Kanai HT, Yaho MY, Sasano EM \& Genta W (2002) Avaliação da brotação e da fertilidade de gemas da videira 'niagara rosada' submetida a diferentes intensidades de poda de frutificação. Semina: Ciências Agrárias, 23:185-190.

Sousa JSI (1996) Uvas para o Brasil. $2^{\text {a }}$ ed. Piracicaba, Fealq. $791 \mathrm{p}$.

Sozim M, Ferreira FP, Ayub RA \& Botelho RV (2007) Época de poda e quebra de dormência em videiras cv. Niagara Rosada. Semina: Ciências Agrárias, 8:201-206.

Tonietto J \& Czermainski ABC (1993) Brotação e fertilidade das gemas da videira 'Cabernet Franc'. Revista Brasileira de Fruticultura, 15:185-192.

Werle T, Guimarães VF, Dalastra IM, Echer MM \& Pio R (2008) Influência da cianamida hidrogenada na brotação e produção da videira 'Niagara Rosada' na região oeste do Paraná. Revista Brasileira de Fruticultura, 30:20-24. 